\title{
Etkileşimli Tahtaların Öğretime Entegrasyonu Konusunda Öğretmen Görüşlerinin Belirlenmesi: Trabzon illi Örneği
}

\author{
Prof. Dr. Hakan Şevki Ayvacı \\ Karadeniz Teknik Üniversitesi-Türkiye \\ hsayvaci@gmail.com
}

\author{
Arş. Gör. Dilek Özbek \\ Karadeniz Teknik Üniversitesi-Türkiye \\ ozbekdilek86@gmail.com
}

Doç. Dr. Serkan Sevim

Pamukkale Üniversitesi-Türkiye

serkansvm@yahoo.com

\begin{abstract}
Özet:
Ülkemizde teknolojinin eğitime entegrasyonu son ylllarda önem kazanmış ve bu kapsamda eğitim ögrretim kurumlarının altyapısının teknolojiye uyumlu olarak yeniden düzenlenmesine yönelik büyük yatırımlar yapılmıştır. Bütün öğretmenlerin aynı anda BT (bilişim teknolojileri) ekipmanlarını derslerine destek amacıyla kullanabilmeleri için her dersliğin etkileşimli tahta ile donatılması ihtiyacı doğmuştur ve bunu gerçekleştirmek için harekete geçilmiştir. Bu bağlamda teknolojinin asıl uygulayıcısı olan ögretmenlerin etkileşimli tahtalar ile ilgili olarak hali hazırda yaşadıkları problemlerin ve hissettikleri ihtiyaçların net bir şekilde tespit edilmesi gerekmektedir. Bu çalışmada etkileşimli tahta kullanımı konusunda öğretmen görüşlerinin derinlemesine ortaya konması amaçlanmıştır. Bu amaç doğrultusunda Trabzon merkeze bağlı 5 ortaokulda görev yapmakta olan ve etkileşimli tahtayı derslerinde kullandığını ifade eden 20 fen bilimleri ögretmeniyle yarı yapılandırılmış görüşmeler yürütülmüştür. Görüşmeler sonucunda öğretmenlerin etkileşimli tahtayı görselliği desteklemek, zamandan tasarruf etmek ve soyut konuları daha somut hale getirmek için kullandıkları, kullanırken teknik problemler ve internet sorunları yaşadıkları ve hizmet içi eğitim eksiklikleri yaşadıkları ortaya çıkmıştır. Bu sonuçlar ışı̆ı̆nda ögretmenlere bu konuda verilebilecek eğitimde dikkat edilecek noktalara yönelik birtakım önerilerde bulunulmuştur.
\end{abstract}

Anahtar kelimeler: Etkileşimli tahta, fen bilimleri öğretmenleri, öğretmen görüşleri, eğitim teknolojileri

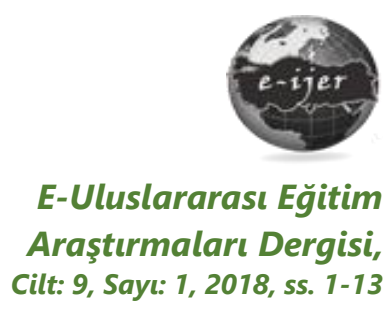

DOI: 10.19160/ijer.361922

Gönderim : 05-12-2017

Revizyon: 15-01-2018 Kabul : 08-04-2018

\section{Önerilen Atıf}

Ayvacı, H. Ş. Özbek, D. \&. Sevim, S. (2018). Etkileşimli Tahtaların Öğretime Entegrasyonu Konusunda Öğretmen Görüşlerinin Belirlenmesi: Trabzon İli Örneği, E-Uluslararası Eğitim Araştırmaları Dergisi, Cilt: 9, Sayı: 1, 2018, ss. 1-13, DOI: 10.19160/ijer.361922 


\section{Giriş}

Hızla gelişen ve değişen dünyamızda uluslararası düzeyde meydana gelen bilimsel, teknolojik ve ekonomik dönüşümler ihtiyaç duyulan yetişmiş insan gücünün özelliklerine de yansımaktadır (Earged, 2011). Bu bağlamda içinde bulunduğumuz yüzyılda yetişen öğrencilerin bilim ve teknolojinin değerini ve bunların toplum ile ilişkisini anlayan, günlük hayatta karşılaştıkları sorunları çözebilecek ve toplumun intiyaçlarına katkıda bulunabilecek becerilere sahip olması beklenmektedir. (Url-1, 2017). Bununla birlikte 21. yüzyılda eğitim sisteminin; bilimsel ve teknolojik gelişmelere ayak uydurabilen, bilgiyi araştırmada, değerlendirmede, aktarmada ve paylaşmada uygun teknolojileri kullanabilen bilgi, medya ve teknoloji okuryazarı bireyler yetiştirmesi gerekmektedir (Uluyol ve Eryılmaz, 2015). 21. yüzyıl becerilerinin öğrencilere kazandırılabilmesi; eğitim standartlarının çağın gerektirdiği nitelikleri karşılayabilecek çerçevede şekillendirilmesini zorunlu kılmaktadır. Bu kapsamda eğitim öğretim ortamları teknolojik ve bilimsel gelişmelere uyumlu olacak şekilde çeşitli ekipmanlarla donatılmış, bilgisayar ve projeksiyon gibi teknolojik cihazlar eğitim ortamlarına dahil edilmeye başlanmış ve teknoloji destekli eğitim öğrenme ortamlarının vazgeçilmez bir parçası haline gelmiştir.

Ülkemizde de teknolojinin eğitime entegrasyonu son yıllarda önem kazanmış ve bu kapsamda eğitim öğretim kurumlarının altyapısının teknolojiye uyumlu olarak yeniden düzenlenmesine yönelik büyük yatıımlar yapılmıştır (Kalkınma bakanlığı, 2007). Bunlardan en önemlisi kuşkusuz 'Eğitim ve öğretimde fırsat eşitliğini sağlamak ve okullardaki teknolojiyi iyileştirmek amacıyla BT araçlarının öğrenme-öğretme sürecinde daha fazla duyu organına hitap edilecek şekilde derslerde etkin kullanımı için; okulöncesi, ilköğretim ile ortaöğretim düzeyindeki tüm okulların 620.000 dersliğine dizüstü bilgisayar, projeksiyon cihazı ve internet altyapısı sağlanmasına yönelik olan FATiH (Fırsatları Artırma ve Teknolojiyi İyileştirme Hareketi) Projesi'dir (Url-2, 2017). Bununla birlikte bütün öğretmenlerin aynı anda BT ekipmanlarını derslerine destek amacıyla kullanabilmeleri için her dersliğin etkileşimli tahta ile donatılması ihtiyacı doğmuştur. Yapılan keşif incelemeleri doğrultusunda ülke genelinde tüm dersliklere etkileşimli tahta kurulumu başlamış olup proje yürütülmeye devam etmektedir.

Son yirmi yılda eğitim ortamlarında kullanılmaya başlanan etkileşimli tahta; bilgisayar ve dijital projeksiyonun bağlanmasıyla çalışan dokunmaya duyarlı bir sunum cihazı olarak tanımlanmaktadır (Adıgüzel, Gürbulak ve Sarıçayır, 2011). İnteraktif tahta olarak da adlandırılan etkileşimli tahtalar, bağlanıldığı bilgisayarda yüklü olan etkileşimli tahta programı ile kullanılmaktadır. Bu program birçok ders için kullanıma hazır kolay çizimler, formüller, resimler, haritalar, şekiller vb. altyapının ders sırasında kolaylıkla kullanımına olanak sağlamaktadır. Aynı zamanda fare işlevi de gören bir kalem aracılığı ile kullanılan tahta, etkileşimli tahta programı dışında bilgisayar ekranı olarak da işlev görmektedir. Bu özelliği sayesinde bilgisayarda yüklü olan ya da bellekte bulunan birçok sunum, video görüntüsü, animasyon ve ofis programları da tahtada rahatıkla açılarak kullanılabilmektedir (Ateş, 2010).

Etkileşimli tahta kullanımına yönelik yapılan çalışmalarda, etkileşimli tahtanın okul öncesinden lisans seviyesine kadar her seviyeden, matematik, coğrafya, güzel sanatlar, dil eğitimi gibi çeşitli derslerde kullanımına yönelik çalışmalara rastlanmaktadır (Güdücü, 2016; Kaynak, 2017; Pektaş Karabekir, 2016; Sessoms 2007; Seyitoğlu, 2014). Bu derslerden biri olan fen bilimleri; doğanın anlaşılmasını ve doğaya ait olguların açıklanmasını amaç edinen fizik, kimya, biyoloji, astronomi, jeoloji ve çevre bilimleri gibi çeşitli bilim dallarını içerisinde barındırmaktadır (MEB, 2013). Bu gibi birçoğu insanoğlunun ortaya çıkmasından bu yana gelişim göstermeye devam eden bilim dallarıyla ilgili temel bilgileri ilk ve ortaokul çağındaki öğrencilere kazandırmak kolay olmayacaktır (Yağbasan ve Gülçiçek, 2003). Somut işlemler döneminden soyut işlem dönemine henüz geçiş yapmakta olan bu bireylerin fen alanına ilişkin soyut kavramları anlamlandırmakta güçlük çekmeleri anlaşılabilir bir durumdur. Bu kapsamda ilköğretim birinci ve ikinci kademe fen bilimleri derslerinde yer alan konuların aktarılmasında yeni teknolojiler çeşitli 
imkânlar sunmaktadır. Ses, resim, grafik, animasyon, benzetim gibi çeşitli materyallerin tek tek veya bir arada kullanılması ile öğrencilerin birden fazla duyu organına hitap edilebilmektedir (Kahyaoğlu, 2011).

Etkileşimli tahtaların sınıf ortamında verimli bir şekilde faaliyet gösterebilmesi öğretmenlerin etkileşimli tahtaya yönelik bilgi, tecrübe ve tutumlarıyla yakında ilişkilidir. Etkileşimli tahta kullanımına yönelik öğretmenlerle yürütülen çalışmalar incelendiğinde etkileşimli tahta kullanımı konusunda öğretmenlerin hem teknik anlamda hem de bilgi eksikliği konusunda zorluk yaşadıkları görülmüştür (Tiryaki ve Çakıroğlu, 2017). Öncelikle teknolojinin asıl uygulayıcısı olan öğretmenlerin etkileşimli tahtalar ile ilgili olarak hali hazırda yaşadıkları problemlerin ve hissettikleri intiyaçların net bir şekilde tespit edilmesi, gelecekte bu teknolojinin kullanımı, yaygınlaştırılması için doğru stratejileri geliştirebilmek adına önem arz etmektedir (Toprakcı, 2006a). Literatür incelendiğinde ülkemizde öğretmenlerin etkileşimli tahtayı son zamanlarda daha etkin bir şekilde kullanmaya başladıkları görülmektedir (Arslan, 2016; Baran, 2010). Bu nedenle de öğretim açısından daha etkili nasıl kullanılabileceğine yönelik yapılacak çalışmalara ihtiyaç olduğu düşünülmektedir (Tataroğlu, 2009; Ormancı, Çepni, Deveci ve Aydın, 2015). Bu bağlamda yürütülen çalışmada etkileşimli tahta kullanımı konusunda öğretmen görüşlerinin derinlemesine ortaya konması amaçlanmıştır. Dolayısıyla araştırmanın, nispeten yeni bir teknoloji olan etkileşimli tahtaların kullanımı ile ilgili literatürdeki eksikliğe ışık tutacağı düşünülmektedir.

\section{YÖNTEM}

\section{Araştırma modeli}

Bu çalışmada nitel araştırma yaklaşımından faydalanılmıştır. Nitel araştırma; gözlem, görüşme ve doküman incelemesi gibi nitel veri toplama tekniklerinin kullanıldığı, algıların ve olayların doğal ortamda gerçekçi ve bütüncül bir biçimde ortaya konmasına yönelik nitel bir sürecin izlendiği araştırma olarak tanımlanmaktadır (Yıldırım ve Şimşek, 2013).

Bu çalışmada etkileşimli tahtayı öğretime dahil etme sürecinin derinlemesine incelemesinin sağlanması ve neden-sonuç ilişkilerinin ortaya koyulmasının amaçlanmasından dolayı özel durum yöntemi tercih edilmiştir. Özel durum, araştırma konusu hakkında derinlemesine bilgi elde etmeyi ve olayı farklı yönleriyle anlamayı amaçlayan bir araştırma yöntemidir (Çepni, 2010). Araştırma kapsamında da akıllı tahtanın öğretmenler tarafından kullanım alanları, faydaları ve karşılaşılan zorlukların ortaya çıkarılması amaçlandığından dolayı bu yöntem uygun görülmüştür.

\section{Çalışma Grubu}

2016-2017 öğretim yılı bahar döneminde Trabzon merkeze bağlı ortaokullarda görev yapmakta olan ve etkileşimli tahtayı derslerinde kullandığını ifade eden 20 fen bilimleri öğretmeni oluşturmaktadır. Katılımcı grubu seçilirken amaçlı örnekleme yöntemi tercih edilmiştir. Zengin bilgiye sahip olduğu düşünülen durumların derinlemesine çalışılmasına olanak tanıdığından dolayı bu örnekleme yöntemi nitel araştırmalarda tercih edilmektedir (Patton 1987). Bu çalışmada Trabzon merkeze bağlı ortaokullarda görev yapmakta olan fen bilimleri öğretmenleriyle yapılan görüşmeler sonucunda kendisine yöneltilen soruları cevaplandırmayı kabul eden ve etkileşimli tahta kullandığını belirten öğretmenlerle yarı yapılandırılmış görüşmeler yürütülmüştür.

\section{Veri Toplama Aracı}

Bu araştırmada, veri toplama aracı olarak yarı yapılandııımış görüşme kullanılmıştır. Kaynakların ulaşılabilirliğine ve araştırmada toplanmak istenen verilerin özelliklerine göre farklı 
şekiller alabilen görüşmeler; yapılandırılmış görüşme, yapılandırılmamış görüşme, yarı yapılandırılmış görüşme, etnografik görüşme ve odak görüşmesi olarak sınıflandırılmaktadır (Büyüköztürk, Çakmak, Akgün, Karadeniz ve Demirel, 2017). Yarı yapılandırılmış görüşmede araştırmacı önceden hazırladığı sorularla birlikte görüşmenin akışına uygun olarak ek sorularla konunun detaylandırılmasını sağlayabilir (Türnüklü, 2000). Yarı yapılandırılmış görüşme soruları hazırlanırken literatürde yapılmış olan çalışmalar dikkate alınmış ve bunlar ışığında öğretmenlerin akıllı tahtaya yönelik görüşlerini ortaya çıkarabilecek sorular belirlenmiştir. Sorular oluşturulduktan sonra bu alanda çalışmalar yürütmüş olan fen eğitimcisi üç öğretim üyesinin uzman görüşü alınarak veri toplama aracına son hali verilmiştir. Bu çalışma süresince Trabzon'daki ilköğretim okulları ziyaret edilip 20 Fen Bilimleri öğretmeniyle görüşme yapılmış ve öğretmenlere görüşmeler esnasında "etkileşimli tahtadan yararlanılan konular, etkileşimli tahtanın kullanım amaçları, etkileşimli tahta kullanımı hakkında öğrenci tutumları, etkileşimli tahta kullanımının faydaları, etkileşimli tahta kullanımı konusunda karşılaşılan zorluklar ve etkileşimli tahta kullanımına yönelik öneriler" olmak üzere toplamda 6 soru yöneltilmiştir. Cevapların yeterli olmadığı durumlarda öğretmenlerin görüşlerini daha detaylı alabilmek amacıyla araştırmacı ek sorular yönlendirmiştir. Öğretmenler tarafından sorulara verilen cevaplar ses kayıt cihazı yardımıyla kayıt altına alınarak görüşmeler sonrasında transkript edilmiştir. Analiz esnasında her bir öğretmen Ö1, Ö2...Ö20 şeklinde kodlanmıştır.

\section{Verilerin Analizi}

Ses kayıtlarının transkriptinden elde edilen veriler içerik analizine tabi tutulmuştur. İçerik analizi belirli kurallara dayalı kodlamalarla bir metnin bazı sözcüklerinin daha küçük içerik kategorileriyle özetlendiği sistematik bir tekniktir. Metin veya metinlerden oluşan bir kümenin içindeki belli kelimelerin veya kavramların varlığını belirlemeye yönelik yapılır. Araştırmacılar bu kelime ve kavramların varlığını, anlamlarını ve ilişkilerini belirler ve analiz ederek metinlerdeki mesajlara ilişkin çıkarımlarda bulunurlar (Büyüköztürk vd, 2017). Bu kapsamda öğretmenlerin akıllı tahtaya yönelik görüşlerinin incelenmesi amacıyla hazırlanan görüşme sorularına verdikleri cevaplar transkript edilerek ham veriler oluşturulmuştur. Bu verilerin incelenmesi sonucunda her bir soruya verilen cevaplara dayalı olarak benzer nitelikteki ifadelerin aynı isimler altında kavramsallaştııılmasıyla kodlar oluşturulmuştur. Yapılan kodlamalar sonucunda ortaya çıkan kodlardan birbiriyle ilişkili kavramları gruplandırarak çeşitli kategoriler oluşturulup bu kategorilerin isimlendirilmesiyle de temalar oluşturulmuş. Araştırmacının yanı sıra veriler fen bilimleri eğitimi alanında uzman bir öğretim elemanı tarafından ayrıca kodlanmış ve bu kodlar araştırmacının elde ettiği kodlarla karşılaştııılarak kodlayıcılar arası tutarlılık oranı 0.81 (Kappa güvenirlik katsayısı) olarak hesaplanmıştır.

\section{BULGULAR}

Katılımcıların Öğretmenlerin etkileşimli tahta kullanımına yönelik görüşlerini ortaya çıkarmak amacıyla öğretmenlerle yürütülen görüşmelerde öğretmenlerin etkileşimli tahta teknolojisinden hangi konularda ve hangi amaçlarla faydalandıkları, öğretmenlerin etkileşimli tahta kullanımında karşılaştıkları öğrenci tutumları, etkileşimli tahtanın kullanımının faydaları hakkındaki düşünceleri, etkileşimli tahta kullanımında karşılaştıkları zorluklar ve etkileşimli tahta kullanımına yönelik önerilerine ilişkin sorular yöneltilmiş ve verilen cevaplar analiz edildikten sonra tablolar halinde sunulmuştur. Öğretmenlerin verdikleri cevaplar görüşme soruları doğrultusunda 6 başıık halinde sunulmuştur.

\section{Etkileşimli tahtadan yararlanılan konulara yönelik öğretmen görüşleri}

Tablo 1 de etkileşimli tahtadan yararlanılan konularla ilgili öğretmen görüşlerine yer verilmiştir. Bu tabloya göre yararlanılan konulara ilişkin kodlar 5 tema altında toplanmıştır. Bu temalar zaman alan konular, mikroboyuttaki kavramlar, makroboyuttaki kavramlar, soyut 
kavramlar ve döngüler ve sistemler olarak adlandırılmıştır. Frekanslar göz önünde bulundurulduğuna öğretmenlerin özellikle maddenin hal değişimi ve genleşme konusunda olduğu gibi deneylerin fazla zaman aldığı konular veya atom, hücre gibi gözle görülemeyecek kadar küçük olan kavramları içeren konularda etkileşimli tahtayı daha sık kullandıkları ortaya çıkmaktadır.

\section{Tablo 1}

Etkileşimli tahtadan yararlanılan konulara yönelik öğretmen görüşleri

\begin{tabular}{|c|c|c|c|c|}
\hline $\begin{array}{l}\text { zaman alan } \\
\text { konular }\end{array}$ & $\begin{array}{l}\text { mikroboyuttaki } \\
\text { kavramlar }\end{array}$ & $\begin{array}{l}\text { makroboyuttaki } \\
\text { kavramlar }\end{array}$ & $\begin{array}{l}\text { soyut } \\
\text { kavramlar }\end{array}$ & $\begin{array}{l}\text { Sistemler ve } \\
\text { döngüsel kavramlar }\end{array}$ \\
\hline $\begin{array}{l}\text { maddenin hal } \\
\text { değişimi } 7 \\
\text { genleşme } 2 \\
\text { fotosentez } 1\end{array}$ & $\begin{array}{l}\text { atom } 5 \\
\text { hücre } 2 \\
\text { genetik } 1 \\
\text { mikroskobik canlılar } 1\end{array}$ & $\begin{array}{l}\text { güneş sistemi } 3 \\
\text { yer kabuğu } 1 \\
\text { deprem oluşumu } 1\end{array}$ & $\begin{array}{l}\text { elektrik } 4 \\
\text { enerji çeşitleri } 1\end{array}$ & $\begin{array}{l}\text { madde döngüleri } 2 \\
\text { vücudumuzdaki } \\
\text { sistemler } 1 \\
\text { enerji dönüşümleri } 1\end{array}$ \\
\hline
\end{tabular}

Yine Tablo 1 de görülebildiği üzere, Güneş Sistemi gibi makrobüyüklükteki kavramlar, elektrik, enerji gibi soyut kavramlar ve sistemler, enerji dönüşümleri gibi döngüsel kavramları içeren konularda etkileşimli tahtanın tercih edildiğine verilerin analizi sonucu ulaşıımıştır. Bu konudaki fikirlerini Ö6 kodlu öğretmen "Hal değişimleriyle ilgili zaman alıcı deneyleri etkileşimli tahta üzerinden gösteriyorum." Şeklinde ifade ederken Ö5 kodlu öğretmen ise görüşlerini "Mikroskobik canlıları bir hayalden anlatmak var bir de görseller yardımıyla anlatmak var. O kadar faydalı ki; sadece görselde görmenin bile o kadar etkisi varken bunu yanında çok güzel animasyonlar da var." Şeklinde dile getirmiştir.

\section{Etkileşimli tahtanın kullanım amaçlarına yönelik öğretmen görüşleri}

Öğretmenlere etkileşimli tahtayı hangi amaçla kullandıklarına ilişkin soru yöneltildiğinde Tablo 2 den de anlaşılabileceği üzere, cevaplarının büyük bir kısmının görsellik ve deneyselleştirme teması altında toplandığı görülmektedir.

\section{Tablo 2}

Etkileşimli tahtanın kullanım amaçlarına yönelik öğretmen görüşleri

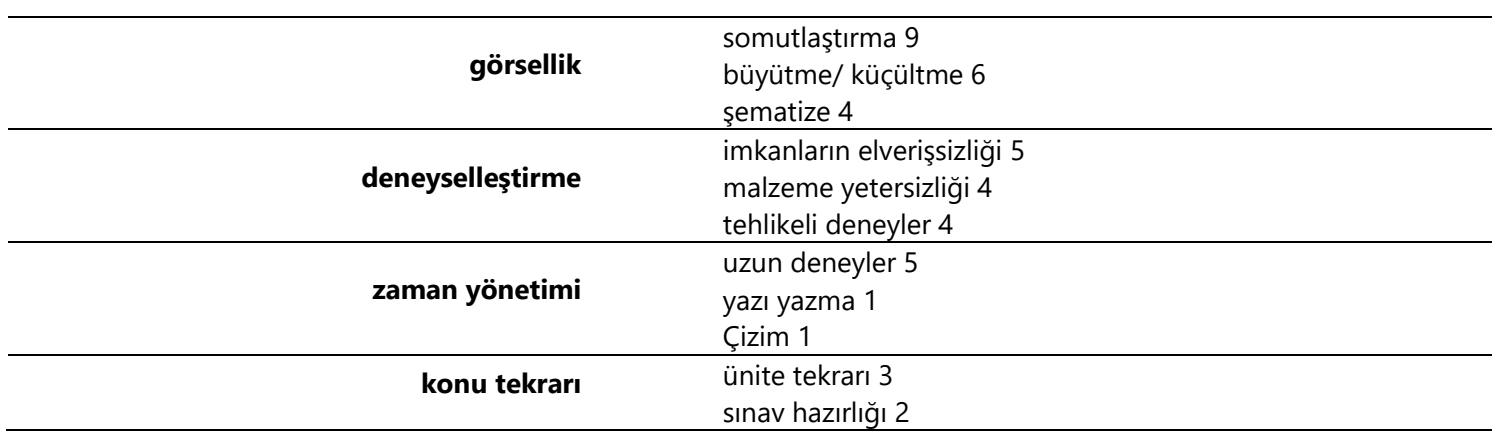

Öğretmenlerden alınan cevaplar incelendiğinde zaman yönetimi, konu tekrarı temalarına yönelik görüş belirttikleri ortaya çıkmaktadır. Öğretmenlerin büyük bir kısmı soyut kavramları somutlaştırmak için görsellere ihtiyaç duyduklarını ve bu ihtiyaçlarını etkileşimli tahta yardımıyla karşıladıklarını belirtmiştir. Bunun yanı sıra bazı deneyleri fiziksel olarak gerçekleştirmek yerine etkileşimli tahtayı tercih ettikleri, yine zaman kaybına yol açan yazım/çizim için etkileşimli tahtadan faydalandıkları ve son olarak konu tekrarı için etkileşimli tahtaya başvurdukları görülmektedir. Örneğin Ö18 "Bazı konular sadece anlatarak geçtiğimiz zaman öğrenciler için çok soyut kalıyor, bunlarla ilgili görselleri, videoları, animasyonları etkileşimli tahtayı kullanarak gösteriyorum." Cümlesiyle bu konudaki görüşünü belirtirken Ö1 ise düşüncelerini "Etkileşimli 
tahtayı genellikle suyun 100 derecede kaynaması gibi tehlikeli deneylerde kullanıyorum." Şeklinde ifade etmiştir. Ö13 ise bu konudaki görüşünü "Konuları pekiştirmek için ünite sonlarında konuları hızlı bir şekilde özetlemek amacıyla etkileşimli tahtadan yardım alıyorum." ifadesiyle dile getirmiştir.

\section{Etkileşimli tahta Kullanımı Hakkında Öğrenci Tutumlarına Yönelik Öğretmen Görüşleri}

Tablo 3'te etkileşimli tahta kullanımına yönelik öğrenci tutumları görülmektedir. Öğretmenlerden alınan cevaplara göre etkileşimli tahta kullanımıyla birlikte öğrencilerde tahtaya çıkma, dersle ilgilenme, hevesli olma ve söz alma gibi aktif katılım belirtileri görülürken etkileşimli tahtayı teknolojik bir ürün olarak algılayan öğrencilerin etkileşimli tahtaya karşı merak ve ilgi duyduğu ve eğlenceli bulduğu öğretmenlerin öğrenci tutumlarına yönelik verdikleri cevaplar arasında yer almaktadır.

Tablo 3

Etkileşimli tahta Kullanımı Hakkında Öğrenci Tutumlarına Yönelik Öğretmen Görüşleri

\begin{tabular}{ll}
\hline aktif katılım & tahtaya çıkma 8 \\
& dersle ilgilenme 8 \\
& hevesli olma 6 \\
& söz alma 3 \\
\hline teknolojik ürün & $\begin{array}{l}\text { eğlenceli bulma 8 } \\
\text { merak uyandırma } 6 \\
\text { ilgi duyma 6 }\end{array}$ \\
\hline
\end{tabular}

Öğretmenler düşüncelerini, Ö1 "Etkileşimli tahtadaki etkinlikler yarışmalar öğrencilerin ilgisini çekiyor ve derse katılmalarını sağlıyor." Şeklinde ifade ederken Ö5 "Öğrenciler teknolojiye çok meraklı ve kullanılmasını istiyorlar. Deneyler, yarışmalar ve tahtadaki testler bile bazen çocuklara eğlenceli gelebiliyor." Sözleriyle görüşlerini dile getirmektedir.

\section{Etkileşimli tahta Kullanımının Faydalarına Yönelik Öğretmen Görüşleri}

Tablo 4'de etkileşimli tahtanın faydaları hakkında öğretmen görüşlerine yer verilmiştir. Öğretmenlerin bu konudaki görüşleri incelendiğinde etkileşimli tahtanın video, resim, simülasyonlarla birlikte kavramları görselleştirmede yarar sağlandığını belirttikleri göze çarpmaktadır.

\section{Tablo 4}

Etkileşimli tahta Kullanımının Faydalarına Yönelik Öğretmen Görüşleri

\begin{tabular}{lllll}
\hline görselleştirme & \multicolumn{1}{c}{ kalıcılık } & ulaşılabilirlik & \multicolumn{1}{c}{ Kolaylık } & Teknoloji \\
\hline video 3 & ilgi çekici 3 & hazır materyal 2 & Yazım/çizim 3 & projeksiyon 3 \\
resim/şekil 3 & farklı duyulara hitap & internet 2 & Etkinlik ve deneyler 3 & bilgisayar 2 \\
simülasyon 2 & etme 2 & testler 1 & Zaman tasarrufu 2 & etkileşim 2 \\
3 boyutlu görsel 2 & örnek çeşitliliği 2 & z kitap 1 & & \\
\hline
\end{tabular}

Etkileşimli tahtanın ilgi çekici olması, birden fazla duyuya hitap etmesi gibi özellikleriyle etkileşimli tahtanın öğrenmeyi daha kalıcı hale getirdiği öğretmen görüşlerinden elde edilen bir diğer temadır. Ayrıca her türlü kaynağa erişim nedeniyle ulaşılabilirliği artırdığı, yazım/çizime kolaylık sağlaması ve bazı etkinlik ve deneyler için kolaylık sağlaması, projeksiyon ve bilgisayarın yerini alması ve etkileşime açık olması nedeniyle teknolojik açıdan faydalı olduğuna yönelik öğretmen görüşleri şekilde görülmektedir. Bu öğretmenlerden Ö19 "Ben gerekli olduğunu düşünüyorum, çocuklar seviyorlar, bizim iş gücümüz biraz daha azaldı kolaylık sağladı, yapamadığımı etkinlikleri oradan yapabiliyoruz." şeklinde görüşünü belirtirken Ö12 ise "Öncesinde projeksiyon kullanıyorduk, fakat bu yalnızca bilgisayar ekranını tahtaya yansıtmamızı sağlıyordu; ama şu an üzerinde istediğimiz gibi çizimler yapabiliyoruz soru çözebiliyoruz." Ifadesiyle düşüncesini dile getirmiştir. 


\section{Etkileşimli tahta Kullanımı Konusunda Karşılaşılan Zorluklar}

Tablo $5^{\prime}$ deki etkileşimli tahta kullanımında karşılaşılan zorluklara yönelik öğretmen görüşleri incelendiğinde sistem hataları, etkileşimli tahtanın yavaşlaması gibi teknik problemlerle internet sorunlarının ön plana çıktığı görülmektedir.

Tablo 5

Etkileşimli tahta Kullanımı Konusunda Karşılaşılan Zorluklar

\begin{tabular}{llll}
\hline teknik problemler & internet sorunları & hizmet içi eğitim & sınıf yönetimi \\
\hline sistem hatası 4 & İnternet bağlantısı sıkıntısı 5 & seminer eksikliği 3 & Oyun algısı 2 \\
yavaşlama 4 & İnternet altyapı sorunu 4 & etkileşim sorunu 2 & Dikkat dağınıklığ 1 \\
dokunmatik ekran 2 & İnternet olmaması 2 & kullanma becerisi 1 & \\
ses-görüntü sorunları 1 & & & \\
& & & \\
\hline
\end{tabular}

Bunun yanı sıra öğretmenlerin bir kısmının etkileşimli tahta kullanımıyla ilgili yetersizliğini dile getirdiği hizmet içi eğitim eksikliği, etkileşimli tahta kullanımının öğrenciler üzerinde oyun algısı yaratması ve dikkat dağınıklığına yol açması gibi sınıf yönetimi sorunlarının ortaya çıkması da etkileşimli tahta kullanırken karşılaşılan zorluklar olarak göze çarpmaktadır. Bu sorunlara ilişkin görüşünü Ö7 "Internet altyapı sorunumuz var, onun haricinde kullanımında bir zorlukla karşılaşmıyoruz." Şeklinde belirtmektedir. Ö13 ise "Bir de henüz kursunu almadığımı için sorun oluyor. Biz şu anda sadece internet kısmını kullanmış oluyoruz. Etkileşim kısmını, çizim özelliklerini kullanamıyoruz." Ifadesiyle görüşlerini dile getirirken, Ö1 kodlu öğretmenin "Bazen sistem hata veriyor ve ekran donup kalıyor bu gibi sıkıntılar olmadığı zaman bir sorunumuz olmuyor." cümlesiyle teknik problemlere vurgu yaptığı görülmektedir.

\section{Etkileşimli tahta kullanımına yönelik öneriler}

Tablo 6'da öğretmenlerin etkileşimli tahta kullanımına yönelik önerilerine ilişkin elde edilen verilerin analizine yer verilmiştir. Buna göre ders sürecinde etkileşimli tahta kullanamama ihtimaline yönelik alternatif bir plan hazırlanması, etkileşimli tahta kullanılacak ders öncesinde ön hazırlık yapılması, ders sürecinde öğrencinin aktif katılımının sağlanması ve etkileşimli tahtayı iyi bir şekilde kullanma becerisine sahip olunması öğretmenlerin önerileri arasındadır.

\section{Tablo 6}

Etkileşimli tahta kullanımına yönelik öneriler

\begin{tabular}{ll}
\hline ders süreci & yardımcı materyal \\
\hline alternatif plan 4 & deney 3 \\
kullanma becerisi 3 & ders kitabı 3 \\
ön hazırlık 2 & yaparak yaşayarak öğrenme 2 \\
aktif katılım 2 & drama 1 \\
\hline
\end{tabular}

Öğretmenlerin cevapları incelendiğinde etkileşimli tahtanın; deneyler, ders kitabı, yaparak yaşayarak öğrenme ve dramanın yanında yardımcı materyal olarak derse katkı sağlaması gerektiği görüşleri göze çarpmaktadır. Örnek olarak Ö1 " $A, B, C$ planlarınızın da olması da gerekiyor. Elektrikler olmayabiliyor, bir B planı uygulamanız gerekebilir ya da elektrik olsa da Eba dondu diyelim, bir C planı gerekli oluyor. Bu aşamada "ben hiçbir şey yokken ne yapabilirim?" bunu düzenleyip en üst aşamasına kadar planınızın olması lazım." Şeklindeki ifadesiyle alternatif bir plana vurgu yaparken Ö5 kodlu öğretmenin ise "Sürekli aynı şeyleri yaparsanız, öğrenci de değişik şeyler aramaya başlar, deney yapacaksanız bizzat öğrenci yapacak, eliyle dokunacak bunu etkileşimli tahtadan göstermek olmaz. Eli dokunsun o iletken tellere, anahtara, duya taksın denesin, takamasın korksun elime elektrik mi çarpacak diye. Pilin uçları ampul dokunsun bir görsün yapsın, yaparak ögrrensin. Her şeyde çok anlamlı olmaz tabi. Yerinde kullanıldığı sürece çok işe yarayacağını tahmin ediyorum." Ifadesiyle görüşlerini dile getirdiği görülmektedir. 


\section{TARTIŞMA, SONUÇ VE ÖNERILER}

Etkileşimli tahta kullanımına ilişkin öğretmenlerin görüşlerini ortaya çıkarmayı amaçlayan bu çalışmada öğretmenlere 6 soru yöneltilmiştir. Yöneltilen bu sorulara verilen cevapların analizi tablolar halinde sunulmuştur. İlk soru olan etkileşimli tahtadan yararlanılan konulara yönelik bulgular incelendiğinde öğretmenlerin bu sorulara verdiği cevapların zaman alan konular, mikro boyuttaki kavramlar, makro boyuttaki kavramlar, soyut kavramlar ve sistemler ve döngüsel kavramlar olmak üzere 5 tema altında toplandığı görülmektedir. Bu bulgular ışığında öğretmenlerin daha çok soyut konu ve kavramların öğretiminde etkileşimli tahtayı tercih ettikleri ortaya çıkmaktadır. Fen bilgisi konularında yer alan kavramların birçoğunun karmaşık ve soyut bir yapıya sahip olması dolayısıyla anlaşılmasında zorlanılan bu konuların öğrencilere aktarımasında etkileşimli tahta benzeri öğretim teknolojilerinden faydalanılacak şekilde ders işleyişlerinin yeniden düzenlenmesi gerekmektedir (Feasy, 2004). Bu nedenle kavramsal anlamanın önemli olduğu fen bilimleri derslerinde etkileşimli tahta kullanımının büyük oranda katkı sağlayacağı söylenebilir (Rutten, Joolingen and Van der Veen, 2012). Yakın zamanda yapılan çalışmalar incelendiğinde fen derslerinde farkı ünitelerde etkileşimli tahtayla birlikte yürütülmüş derslerin öğrenci başarısını arttırdığı görülmüştür (Dereli, 2016; Kaynak, 2017).

Ardaç ve Akaygün (2004), atom ve molekül gibi soyut kavramların öğretilmesinde simülasyonların kullanılmasının öğrencilerin kavrama düzeylerini arttırdığını öne sürmektedir. Bu bağlamda etkileşimli tahta yardımıyla kullanılacak simülasyon, animasyon vb. etkinliklerin soyut ve gözlenemeyen kavramların görsellestirilmesiyle öğrenmeyi desteklediği sonucuna ulaşılabilir. Bununla birlikte fen derslerinde kullanılacak olan bilgi ve iletişim teknolojileri, günlük hayatta gözlemlenemeyecek moleküler ve mikroskobik boyuttaki fen olaylarını görselleştirme imkanı sunmaktadır (Pekdağ, 2010).

Öğretmenlere etkileşimli tahtayı hangi amaçla kullandıklarına ilişkin yöneltilen sorunun cevapları incelendiğinde öğretmenlerin bazı deneyleri fiziksel olarak gerçekleştirmek yerine etkileşimli tahtayı tercih ettikleri bunun sebebi olarak da bazı deneyleri gerçekleştirmenin tehlikeli olmasını veya uzun zaman almasını, bununla birlikte bazı durumlarda imkanların elverişsizliğini ve malzeme yetersizliğini öne sürdükleri görülmektedir. Dolayısıyla etkileşimli tahtayla kullanılabilecek simülasyon, animasyon, multimedya gibi öğretim teknolojilerinin yüksek maliyetli veya tehlikeli kimyasalların kullanımını gerektirmesinden dolayı geleneksel yöntemlerle oluşturulamayacak deney ortamlarının gerçekleştirmesine olanak sağlayacağı söylenebilir (Yang ans Heh, 2007). Bununla birlikte etkileşimli tahta üzerinde gerçekleştirilecek deneyler değişkenliklerin değiştirilebilmesi, bunun etkilerinin gözlemlenebilmesi ve deneyin istenilen sayıda tekrarlanmasına olanak verecektir (De Jong, 2006). Bu bağlamda, sanal laboratuvar uygulamalarıyla ilgili çalışmalar yürütülmekte olup bu laboratuvar türünün geleneksel laboratuvar yöntemiyle kıyaslandığında öğrencilerin deneyleri daha ucuz maliyetle daha kısa sürede yapmalarına olanak sağladığı öne sürülmektedir (Bozkurt ve Sarıkoç, 2008; Ulukök, Çelik ve Sarı, 2013).

Öğretmenlerin etkileşimli tahta kullanımına ilişkin değindikleri bir diğer noktanın zaman yönetimi olduğu göze çarpmaktadır. Yöneltilen farklı sorularda zaman yönetimine ilişkin görüş belirten öğretmenlere göre etkileşimli tahta kullanımının birçok açıdan zaman tasarrufu sağladığı söylenebilir. Bu bakımdan kapsamlı hazırlık gerektiren etkinlik ve deneyleri gerçekleştirmek yerine kullanılacak videolar hem zaman tasarrufu sağlayacak hem de etkili bir öğretme aracı olacaktır (Karakuş ve Karakuş, 2017; Laroche, Wulfsberg and Young, 2003). Ayrıca fen derslerinde kullanılacak simülasyonlar, öğrencilerin konuyu zaman kısıllaması olmadan kendilerine uygun şekilde gözden geçirerek öğrenme hızını kendilerine göre ayarlamalarına imkan tanıyacaktır (Sönmez, 2006).

Etkileşimli tahta ile öğretimin birden fazla duyuya hitap etmesi nedeniyle öğretimin görseller, videolar, simülasyonlarla zenginleştirilmesinin öğrenmeye katkı sağladığı ve bilgiyi daha kalıı hale getirdiği etkileşimli tahta kullanımıyla ilgili öğretmenlerin vurguladığı özellikler arasında yer almaktadır (Beauchamp and Parkinson, 2005; Cogill, 2002; Sağlam, 2007). Ayrıca 
birçok duyuyu harekete geçirmesi nedeniyle etkileşimli tahta kullanımı konuyu ilgi çekici kılmakta dolayısıyla derse katıımı ve motivasyonu arttırmaktadır (Altınçelik, 2009; Preston ve Mowbray, 2008).

Öğretmenler etkileşimli tahta kullanımında karşılaşılan zorluklara ilişkin görüşlerini belirtirken teknik problemlere ve internet sorunlarına değinmiştir. Etkileşimli tahtaya ilişkin sistem hatası, kalibrasyon işlemi, projeksiyon sıkıntısı gibi teknik aksaklıkların yanı sıra yazılımların kalitesizliği, alt yapı ve donanım eksikliği gibi faktörler okullarda etkileşimli tahtanın yeterince kullanılamamasına sebep olmaktadır (Arslan, 2016; Çoklar ve Tercan, 2014; Türel, 2012).

Öğretmenlerin etkileşimli tahtaya yönelik görüşlerinden elde edilen cevaplar incelendiğinde etkileşimli tahtayı kullanmaya yönelik hizmet içi eğitim eksikliği yaşadıklarını, bu nedenle de kullanma becerilerinin zayıf olduğunu dile getirdikleri görülmektedir. Yapılan bazı araştırmalarda ise öğretmenlerin etkileşimli tahta gibi öğretim teknolojilerini etkili kullanamama sebepleri arasında öğretmenlerin teknolojiye yönelik negatif tutuma ve teknolojinin eğitim ortamlarına entegrasyonu, özellikle bilgisayar yazılımları konusunda yetersiz bilgiye sahip olmaları gösterilmektedir (Çakır ve Yıldııım, 2009; Sezgin, Erdoğan ve Erdoğan, 2017). Bu bakımdan, öğretmenlere verilecek olan hizmet içi eğitim kurslarının titizlikle planlanması gerekmektedir (Toprakcı, 2006b). Verilen hizmet içi eğitim kursları yeterli olmadığı takdirde öğretmenlerin teknoloji kullanım düzeylerini değiştirmede etkili olmayacaktır (Güven ve Kaleli Yılmaz, 2016). Başak ve Ayvacı (2017) öğretmenlerin eksikliklerini gidermeye yönelik hazırlanan hizmet içi eğitim kurslarında birtakım düzenlemeler yapılması gerektiğini aksi halde etkileşimli tahtadan yeterince verim alınamayacağını belirtmiştir. Bu bakımdan özellikle fen bilimleri öğretmenlerinin yeni teknolojilerle donatılmış öğrenme ortamları sunabilmeleri, bu teknolojileri entegre edebilmek için gerekli bilgi, beceri ve yeterliliğe sahip olmalarını gerektirmektedir (Kahyaoğlu, 2011). Zira günümüzde $Z$ kuşağı olarak da adlandırılan dijital nesil teknolojiyle çok daha erken yaşlarda tanıştığından ve günlük yaşamında teknolojiyi daha aktif kullandığından dolayı sınıf ortamında teknolojiyi kullanmakta sıkıntı yaşamayan ve her şekilde teknolojiden faydalanmayı bilen öğretmenlerle çalışmayı tercih etmektedir (Güven, 2006).

Öğretmenlerin cevapları incelendiğinde, etkileşimli tahtayı soyut konuların anlatımında kullanmayı tercih ettikleri sonucuna ulaşımıştır. Bu bakımdan somut konuların anlatımında da etkileşimli tahta kullanımının öğretimde etkililiğine yönelik çalışmalar yapılmalı ve bu çalışmaların sonuçları öğretmenlerle de paylaşılmalıdır.

Etkileşimli tahtanın, dersi hızlandırmaktan ziyade öğretim ortamını zenginleştiren bir materyal olduğu öğretmenlere vurgulanmalıdır. Öğretmenler daha hızlı soru çözme, daha kolay modelleme ve çizim yapma ya da daha kısa sürede gösteri deneyi ve simülasyon yapma alışkanlıklarından uzaklaştıılarak etkileşimli tahtanın ders sürecindeki öğretimi kolaylaştırıcı rolü ön plana çıkarılmalıdır.

Etkileşimli tahtanın sınıf içi uygulayıcıları olan öğretmenlerin etkileşimli tahta kullanımına yönelik eksik olan yönlerinin belirlenmesi ve buna uygun bir hizmet için eğitim planı hazırlanması gerekmektedir. Burada dikkat edilmesi gereken nokta, öğretmenlere yönelik hazırlanan hizmet içi eğitim kurslarının etkileşimli tahtaya ilişkin öğretmenlerin teknoloji bilgisinin yanı sıra teknolojik pedagojik alan bilgilerini de artırmaya yönelik olmalıdır.

\section{KAYNAKÇA}

Adıgüzel, T., Gürbulak, N., Sarıçayır, H. (2011). Akıllı Tahtalar ve Öğretim Uygulamaları. Mustafa Kemal Üniversitesi Sosyal Bilimler Enstitüsü Dergisi, 15 (8),457-471.

Altınçelik, B. (2009). Ilköğretim düzeyinde öğrenmede kalıclığı ve motivasyonu sağlaması yönünden akıllı tahtaya ilişkin ögrretmen görüşleri. Yayımlanmamış Yüksek Lisans Tezi, Sakarya Üniversitesi Sosyal Bilimler Enstitüsü, Sakarya.

Ardac, D., and Akaygün, S. (2004). Effectiveness of multimedia-based instruction that emphasizes molecular representations on students' understanding of chemical change. Journal of Research in Science Teaching, 41(4), 317-337. 
Arslan, Z. (2016). Eğitim Bilişim Ağı́ndaki matematik dersi içeriğine ilişkin öğretmen görüşleri: Trabzon ili örneği. Yayınlanmamış yüksek lisans tezi, Karadeniz Teknik Üniversitesi, Eğitim Bilimleri Enstitüsü, Trabzon.

Ateş, M. (2010). Ortaöğretim coğrafya derslerinde akıllı tahta kullanımı. Marmara Coğrafya Dergisi, 22(1), 409 - 427.

Baran, B. (2010). Experiences from the process of designing lessons with interactive whiteboard: ASSURE as a road map. Contemporary Educational Technology, 1(4). 367-380.

Başak, M. H., ve Ayvacı, H. Ş. (2017). Teknoloji entegrasyonunun eğitim alanında uygulanmasına yönelik bir karşılaştırma: Türkiye-Güney Kore örneği. Eğitim ve Bilim, 42(190). 465-492.

Beauchamp, G., and Parkinson, J. (2005). Beyond the 'wow'factor: developing interactivity with the interactive whiteboard. School Science Review, 86(316). 97-103.

Bozkurt, E., ve Sarıkoç, A. (2008). Fizik eğitiminde sanal laboratuvar, geleneksel laboratuvarın yerini tutabilir mi. Selçuk Üniversitesi Ahmet Keleşoğlu Eğitim Fakültesi Dergisi, 25, 89-100.

Büyüköztürk, Ş., Çakmak, E. K., Akgün, Ö. E., Karadeniz, Ş., ve Demirel, F. (2017). Bilimsel araştırma yöntemleri. Ankara: Pegem yayıncilık. 1-360.

Cogill, J. (2002). How is the interactive whiteboard being used in the primary school and how does this affect teachers and teaching. Retrieved November, 6. 1-48

Çakır, R., ve Yıldırım, S. (2009). Bilgisayar öğretmenleri okullardaki teknoloji entegrasyonu hakkında ne düşünürler? ilköğretim Online, 8(3). 952-964

Çepni, S. (2010). Araştırma ve Proje Çalışmalarına Giriş. Ankara: Pegem A Yayınıılık

Çoklar, A. N. ve Tercan, İ. (2014). Akıllı tahta kullanan öğretmenlerin akıllı tahta kullanımına yönelik görüşleri. Illköğretim Online, 13(1). 48-61.

De Jong, T. (2006). The design of effective simulation-based inquiry learning environments. Frontiers in Artificial Intelligence And Applications, 151, 3.

Dereli, F. (2016) 6. sınıf dünya ve evren konu alanına uyarlanmış bilimin doğası kazanımlarının akıllı tahta etkinlikleri ile ögretimi. Yayınlanmamış Yüksek Lisans Tezi, Mehmet Akif Ersoy Üniversitesi, Eğitim Bilimleri Enstitüsü, Burdur.

Earged (2011). MEB 21. yüzyıl öğrenci profili, http://www.meb.gov.tr/earged/earged/21.\%20yy_og_pro.pdf (Erişim tarihi; 16.03.2018)

Feasy, R. (2004). "Thinking and working scientifically", (44-87). In Skamp, K. (Ed.), Teaching primary science constructively (I2nd ed.). Southbank Victoria: Thomson.

Güdücü, T. (2016). Erken yaşta Ingilizce öğrenenlerin öğretmenlerinin Ingilizce sınıflarında akıllı tahta kullanımına karşı algıları ve karşılaşılan zorluklar. Yayınlanmamış Yüksek Lisans Tezi. Bahçeşehir Üniversitesi, Eğitim Bilimleri Enstitüsü. İstanbul.

Güven, B., ve Kaleli Yılmaz, G. (2016). Tasarlanan Hizmet-içi Eğitim Kursunun Ortaokul Matematik Öğretmenlerinin Teknoloji Kullanım Düzeylerine Etkisi. Eğitim ve Bilim, 41(188), 35-66.

Güven, S. (2006). Öğretim teknolojileri ve materyal geliştirme dersinin kazandırdığı yeterlikler yönünden değerlendirilmesi (İnönü Üniversitesi eğitim fakültesi örneği). Türk Eğitim Bilimleri Dergisi, 4 (2), 165-179.

Kahyaoğlu, M. (2011). İlköğretim öğretmenlerinin fen ve teknoloji dersinde yeni teknolojileri kullanmaya yönelik görüşleri. Eğitim Bilimleri Araştırmaları Dergisi, 1(1), 79-91.

Kalkınma Bakanlığı (2007), "Dokuzuncu Kalkınma Planı (2007-2013)", http://www.kalkinma.gov.tr/Lists/Kalknma\%20Planlar/Attachments/1/plan9.pdf (Erişim Tarihi: 15.03.2018)

Karakuş, İ., \& Karakuş, S. (2017). Akıllı Tahta Kullanımına Yönelik Ortaöğretim Öğretmenlerinin Görüşlerinin İncelenmesi. Turkish Journal of Educational Studies, 4(2). 1-37.

Kaynak, S. (2017) 7.sınıf insan ve çevre ünitesinde akıllı tahta kullanımının öğrenci başarısına, tutumuna ve hatırlama düzeyine etkisi. Yayınlanmamış Yüksek Lisans Tezi, Necmettin Erbakan Üniversitesi, Eğitim Bilimleri Enstitüsü, Konya.

Laroche, L. H., Wulfsberg, G., and Young, B. (2003). Discovery videos: A safe, tested, timeefficient way to incorporate discovery-laboratory experiments into the classroom. Journal of Chemical Education, 80(8), 962-966.

MEB (2013). Talim ve Terbiye Kurulu Başkanlığı İlköğretim Kurumları (Illkokullar ve Ortaokullar) Fen Bilimleri Kitabı

Ormanci, U., Cepni, S., Deveci, I., and Aydin, O. (2015). A thematic review of interactive whiteboard use in science education: rationales, purposes, methods and general knowledge. Journal of Science Education and Technology, 24(5), 532-548.

Patton, M.Q. (1987) How to Use Qualitative Methods in Evaluation. Newbury Park, CA: Sage. 
Pekdağ, B. (2010). Kimya öğreniminde alternatif yollar: animasyon, simülasyon, video ve multimedya ile öğrenme. Türk Fen Eğitimi Dergisi, 7(2), 79-110.

Pektaş Karabekir, E. (2016). Akıllı tahta araculığıla sunulan video modelle öğretimin otizmli çocuklara sosyal tepki davranışlarının öğretimindeki etkililiği. Yayınlanmamış Yüksek Lisans Tezi. Anadolu Üniversitesi, Sosyal Bilimler Enstitüsü. Eskişehir.

Preston, C., and Mowbray, L. (2008). Use of SMART boards for teaching, learning and assessment in kindergarten science. Teaching Science, 54(2), 50-53.

Rutten, N., Joolingen, W. R., and Van der Veen, J. T. (2012). The learning effects of computer simulations in science education. Computers and Education, 58, 136-153.

Sağlam, F. (2007). ilköğretim okullarında görev yapan öğretmenlerin derslerinde bilgi teknolojisi yararlanma öz yeterlilikleri ve etki algılarının belirlenmesi, Basılmış Yüksek Lisans Tezi, Yeditepe Üniversitesi Sosyal Bilimler Enstitüsü, İstanbul.

Sessoms, D. (2007). Using interactive boards to enhance teaching and learning for students with learning disabilities. In Society for Information Technology and Teacher Education International Conference, 3648-3653. Association for the Advancement of Computing in Education (AACE).

Seyitoğlu, E. (2014). Akıllı tahta kullanılan matematik dersinden yansımalar. Yayınlanmamış Yüksek Lisans Tezi. Karadeniz Teknik Üniversitesi, Eğitim Bilimleri Enstitüsü. Trabzon.

Sezgin, F., Erdoğan, O., ve Erdoğan, B. H. (2017). Öğretmenlerin teknoloji öz yeterlikleri: Öğretmen ve öğrenci görüşlerine yönelik bütüncül bir analiz. Eğitim Teknolojisi Kuram ve Uygulama, 7(1), 180-199.

Sönmez, N. (2006). Iki değişken arasındaki ilişki ile ilgili iki simülasyon deneyinde öğretim desteğinin öğrenim kazanımları üzerindeki etkisi. Yayımlanmamış Yüksek lisans tezi, Bogaziçi Univesitesi, Fen Bilimleri Enstitüsü, İstanbul.

Tataroğlu, B. (2009). Matematik öğretiminde akıllı tahta kullanımının 10. sınıf öğrencilerinin akademik başarıları, matematik dersine karşı tutumları ve öz-yeterlik düzeylerine etkileri. Yayımlanmış Yüksek Lisans Tezi, Dokuz Eylül Üniversitesi, Eğitim Bilimleri Enstitüsü, İzmir.

Tiryaki, A. ve Çakıroğlu, Ö. (2017). Fen bilimleri öğretiminde akıllı tahta kullanımı. Behiye Akçay (Ed.), Fen bilimleri eğitimi alanındaki öğretme ve ögrenme yaklaşımları (213-224). Ankara: Pegem yayıncılık.

Toprakci, E. (2006a). Obstacles at integration of schools into information and communication technologies by taking into consideration the opinions of the teachers and principals of primary and secondary schools in Turkey. Journal of Instructional Science and Technology (e-JIST), 9(1), 1-16.

Toprakci, E. (2006b). Perceptions Related to Information and Communication Technologies (ICT) by Managers and Teachers in the Primary and the Secondary Schools (The Example of Sivas). Eurasian Journal of Educational Research (EJER), (24).

Türel Y.K. (2012). Öğretmenlerin Akıllı tahta Kullanımına Yönelik Olumsuz Tutumları: Problemler ve İhtiyaçlar, Elementary Education Online, 11, 423-439

Türnüklü, A. (2000). Eğitimbilim araştırmalarında etkin olarak kullanılabilecek nitel bir araştırma tekniği: Görüşme. Kuram ve Uygulamada Egitim Yönetimi Dergisi, 6(4), 543-559.

Ulukök, Ş., Çelik, H., ve Sarı, U. (2013). Basit elektrik devreleriyle ilgili bilgisayar destekli uygulamaların deneysel süreç becerilerinin gelişimine etkisi. Kuramsal Eğitimbilim Dergisi, 6 (1), 77-101.

Uluyol, Ç. ve Eryılmaz, S. (2015). 21. Yüzyıl Becerileri Işığında FATiH Projesi Değerlendirmesi. Gazi Üniversitesi Gazi Eğitim Fakültesi Dergisi, 35(2), 209-229.

Url-1, (2017). Partnership for 21. Century learning. http://www.p21.org/our-work/p21-framework (Erişim tarihi 16.03.2018)

Url-2, (2017). http://fatihprojesi.meb.gov.tr/ (Erișim tarihi 16.03.2018)

Yağbasan, R., ve Gülçiçek, A. G. Ç. (2003). Fen öğretiminde kavram yanılgılarının karakteristiklerinin tanımlanması. Pamukkale Üniversitesi Eğitim Fakültesi Dergisi, 13(13), 102-120.

Yang, K. Y. and Heh, J. S. (2007). The impact of internet virtual physics laboratory instruction on the achievement in physics, science process skills and computer attitudes of 10th-grade students. Journal of Science Education and Technology 16, 451-461.

Yıldırım, A., ve Şimşek, H. (2013). Sosyal bilimlerde nitel araştırma yöntemleri. (9. Genişletilmiş Baskı) Ankara: Seçkin Yayınevi. 


\title{
Determining Teachers' Opinions towards the Integration of Interactive Boards into Teaching: Trabzon Sample
}

\author{
Prof. Dr. Hakan Şevki Ayvacı \\ Karadeniz Technical University-Turkey \\ hsayvaci@gmail.com
}

\author{
Ress.Ass.Dilek Özbek \\ Karadeniz Technical University-Turkey \\ ozbekdilek86@gmail.com
}

\author{
Assoc.Prof.Dr. Serkan Sevim \\ Pamukkale University-Turkey \\ serkansvm@yahoo.com
}

\begin{abstract}
In recent years, integration of technology into education in Turkey has gained importance and significant investments have made to rearrange the educaitonal institutions' infrastructure in order to adapt technology. Along with that, all teachers need to equip their classrooms with interactive boards to support their lessons with IT eqiupments. In order to generalize the actively using of interactive boards in classrooms, teachers' troubles and needs should be determined. In this case, the purpose of this study is to investigate the science teachers' opinions towards interactive boards. The study group of this research consists of 20 science teachers who claimed to use interactive boards actively in their classroom practices. The data obtained from the analysis of the conducted interviews to determine the opinions of teachers' common subjects used with interactive boards, purposes of using interactive boards, students' attitudes towards interactive boards, benefits of using interactive boards, challenges of using interactive boards and suggestions towards using interactive boards.

Keywords: Interactive board, science teachers, teachers' opinion, educational technology
\end{abstract}

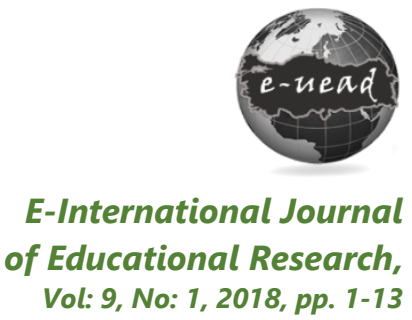

DOI: 10.19160/ijer.361922

\section{Suggested Citation:}

Ayvacı, H. Ş. Özbek, D. \&. Sevim, S. (2018). Determining Teachers' Opinions towards the Integration of Interactive Boards into Teaching: Trabzon Sample, E-International Journal of Educational Research, Vol:9, No: 1, 2018, pp. 1-13, DOI: 10.19160/ijer.361922 


\section{EXTENDED ABSTRACT}

Problem: In recent years, integration of technology into education in Turkey has gained importance and significant investments have made to rearrange the educaitonal institutions' infrastructure in order to adapt technology. Along with that, all teachers need to equip their classrooms with interactive boards to support their lessons with IT eqiupments. Setting up interactive boards to the classrooms all across the country is an on going project in these days.

According to the recent studies interactive boards are used in various lessons such as mathematics, geography, fine arts, foreign languages from kindergarden to the undergraduate level (Sessoms 2007; Seyitoğlu, 2014; Güdücü, 2016; Pektaş Karabekir, 2016; Kaynak, 2017). Being one of the lessons interactive boards are used actively, science lesson is commonly consist of abstract and complex subjects. New educational technologies support teaching these subjects to the students with the stimulation of visual and auditory senses. (Kahyaoğlu, 2011). Usage of interactive boards in classrooms depends on teachers' knowledge, experience and attitudes towards interactive boards. In order to generalize the actively using of interactive boards in classrooms, teachers' troubles and needs should be determined. In this case, the purpose of this study is to determine the science teachers' opinions towards interactive boards.

Method: In this study, qualitative research patterns are used to determine teachers' in-depth opinions towards interactive boards. The study group of this research consists of 20 science teachers whom use interactive boards actively in their classroom practices. To determine science teachers' opinions, semi structured interviews were used. The data collection tool was developed by the researchers and it was consist of six questions. The interviews were recorded by the researcher and transcripted after the interviews. Data were analyzed with. content analysis technique and obtained codes and themes were presented by figures.

Findings: The data obtained from the analysis of the conducted interviews to determine the opinions of teachers' common subjects used with interactive boards, purposes of using interactive boards, students' attitudes towards interactive boards, benefits of using interactive boards, challenges of using interactive boards and suggestions towards using interactive boards. When the first figure was examined, it is seen that teachers generally use interactive boards with micro-sized concepts such as atoms, cell, genetic, macro-sized concepts such as Solar system, earth crust, abstract concepts such as electricity and types of energy, cycles and systems such as matter cycle, energy cycles and the concepts that take a lot of time such as expansion and photosynthesis. Second, teachers were asked the purposes of using interactive boards. When the results are examined; it can be understood that teachers use the purposes of using interactive boards for visualizing abstract subjects, instead of experimenting in dangerous subjects, for time management, for repeating the subject before or after the lessons and for preparing the students for exams. The third question asked to teachers was about students' attitudes towards interactive boards. According to the teachers' opinion first theme is active participation and second theme is technological product. When teachers' answers towards the benefits of using interactive boards were analyzed, it is found that visualizing such as videos, graphics, figures, 3d visuals, simulations; permanent learning such as attractivity, variety of examples; availability such as ready materials, internet, e-books, convenience and technology such as projector and computer. Teachers also mentioned technical problems such as system error, slowing, sound and image problems; internet problems such as internet connection; in-service training such as lack of seminar and the ability of using interactive boards and classroom management problems about challenges of using interactive boards during the interviews. Finally, analyzed data about teachers' suggestions towards using interactive boards consist of two themes time course and supportive materials. 